AOS - Amazônia, Organizações e Sustentabilidade

Amazon, Organizations and Sustainability

v.9, n.2, ago./dez. 2020, p.294-311

DOI - http://dx.doi.org/10.17648/aos.v9i2.1292

ISSN on-line: $2238-8893$

\title{
EVOLUÇÃO DO RELATÓRIO DE SUSTENTABILIDADE GLOBAL REPORTING INITIATIVE - GRI: 20 ANOS DE APLICAÇÃO \\ EVOLUTION OF THE GLOBAL REPORTING INITIATIVE \\ - GRI SUSTAINABILITY REPORT: 20 YEARS OF APPLICATION
}

\author{
Rosany Corrêa $\boldsymbol{I}^{1}$ \\ Henrique César Melo Ribeiro ${ }^{2}$
}

\begin{abstract}
Resumo
O estudo verificou através do Report List GRI desde sua publicação em 1999 até 2018, o nível de evolução destes relatórios de sustentabilidade da Global Reporting Initiative nas empresas do Brasil e do mundo. A GRI tem suas bases de relatórios na quarta geração do modelo, GRI-G4, o que mostra um empenho na melhoria contínua dos indicadores e sua adoção por diferentes países. Foi realizada uma pesquisa bibliográfica e uso de dados secundários. A pesquisa mostrou que houve evolução na aplicação dos relatórios. Confirmando a consolidação e a legitimação da metodologia da GRI de divulgação de relatórios de sustentabilidade. As Diretrizes da GRI G4 representam um código de conduta e um padrão de desempenho, vistos com materialidade, evidenciado nas 3235 empresas que usam esse nível no mundo, dos quais $6 \%$ são empresas brasileiras, propiciando assim maior credibilidade das informações socioambientais aos seus stakeholders.
\end{abstract}

Palavras-chave: Indicadores de sustentabilidade. Relatório de sustentabilidade. Global Reporting Initiative.

\section{Abstract}

The objective of the article is to verify the level of adoption and evolution of sustainability reports of the Global Reporting Initiative - GRI in companies. GRI has its reporting bases in the fourth generation of the GRI-G4 model, which shows a commitment to the continuous improvement of indicators and their adoption by different countries. The methodology used was qualitative, through a bibliographical survey and secondary data. As a tool for analysis, the GRI Report List was adopted since its publication in 1999 until 2018. The analysis showed a significant evolution in the adoption of the GRI model by

1 Doutora em Administração pela Universidade Nove de Julho. Professora Adjunta da Universidade Estadual do Piauí (UESPI). Parnaíba, PI e Brasil. E-mail:rosanycorrêa@ hotmail.com.

2 Doutor em Administração pela Universidade Nove de Julho. Professor Adjunto da Universidade Federal do Delta do Parnaíba (UFDPar). Parnaíba, PI e Brasil.E-mial:hcmribeiro@gmail.com

\section{4}


companies in the three levels, world, Brazil and Corporate Sustainability Index. The survey results show the ongoing evolution of the reports, in search of the most improved level of sustainability report, and with significant adoption in Brazil, which legitimizes the Global Reporting Initiative's sustainability reporting model.

Key words: Sustainability indicators. Sustainability report. Global Reporting Initiative.

\section{INTRODUÇÃO}

Os impactos ocasionados pelas empresas como dejetos e degradação ambiental estão ligados ao desenvolvimento econômico que além da geração da riqueza deixa um rastro de destruição do meio natural. Medidas são tomadas por governos e por empresas para mitigar os efeitos negativos das organizações sobre o meio ambiente. Segundo Sachs (1997), o conceito de desenvolvimento sustentável refere-se a uma nova concepção de limites e reconhecimento das fragilidades do planeta, ao mesmo tempo em que enfoca o problema socioeconômico e da satisfação das necessidades básicas da população (COELHO et. al., 2018). O relatório Nosso Futuro Comum (Comissão Mundial Sobre o Meio Ambiente e Desenvolvimento, 1991) define desenvolvimento sustentável como aquele que satisfaz as necessidades do presente sem comprometer a capacidade das gerações futuras de suprir suas próprias necessidades.

A responsabilidade ambiental das organizações é pauta de discussões de forma intensa, e recentemente uma parcela da sociedade se tornou mais exigente com a origem e a sustentabilidade dos produtos (DOMENICO; TORMEM; MAZZIONI, 2017). E a organização que adota a responsabilidade socioambiental presta contas de seu desempenho, econômico, ambiental e social através da elaboração de relatórios de sustentabilidade para divulgar às partes interessadas (FARIA, 2017) sua responsabilidade ambiental. Dessa forma, surgem modelos de indicadores e de relatórios que orientam a implantação e os controles das empresas que desenvolvem ações de sustentabilidade (CORREA et.al, 2012), a divulgação de informações ambientais retrata a estratégia das empresas em relação ao meio ambiente (MOTA et.al., 2011).

No Brasil os relatórios de sustentabilidade em uso são o do Instituto Ethos (2011) e o da Global Reporting Initiative - GRI, que apresentou um crescimento significativo na última década em número de empresas que utilizam essa metodologia. O conjunto de diretrizes e indicadores da GRI proporciona a comparabilidade, credibilidade, periodicidade e legitimidade da informação na comunicação do desempenho social, ambiental e econômico das organizações que utilizam a metodologia (GRI, 2006; LEITE FILHO et.al.,2009). O intuito da divulgação ambiental, então, seria o de informar o desempenho ambiental da organização demonstrando aos stakeholders suas intenções e iniciativas para evitar a degradação do meio ambiente (MOTA et.al., 2011).

A evolução da geração dos modelos da GRI mostra um empenho na melhoria contínua dos indicadores e sua adoção por diferentes países. Os relatores devem declarar o nível aplicado à estrutura de relatório usando o GRI-G3. Os níveis evidenciam um ponto de partida para organizações que elaboram o relatório pela primeira vez, incentivando e reforçando a importância de uma abordagem progressiva para a elaboração de relatórios que aumenta a exigibilidade ao longo do tempo (CORREA et. al, 2012). Esses relatos podem ocorrer de forma autodeclarada ou pela verificação externa. Os três níveis de aplicação do relatório são intitulados A, B e C. Os critérios de relato encontrados em cada 
um dos níveis indicam a evolução da aplicação ou cobertura da estrutura de relatórios da GRI. Uma organização poderá autodeclarar um ponto a mais (+) em cada nível (por exemplo, $\mathrm{C}+, \mathrm{B}+, \mathrm{A}+$ ), caso tenha sido utilizada verificação externa do relatório (GRI, 2006).

Em 2014 foi realizada a quarta conferência global da GRI, intitulada "Informação - Integração Inovação", reuniu 1.600 delegados de 69 países. Concomitantemente, a GRI divulgou a quarta geração de suas Diretrizes, G4, oferecendo Princípios de Relato, Divulgações Padrão e um Manual de Implementação para a preparação de relatórios de sustentabilidade por organizações de qualquer tamanho ou setor. $\mathrm{O}$ G4 Online foi lançado alguns meses depois, uma ferramenta gratuita baseada na Web que apresenta o conteúdo completo das Diretrizes G4 em um formato dinâmico para aqueles que já estão familiarizados com os Princípios de Relatórios e as Divulgações Padrão das Diretrizes G4. (GRI, 2017).

Passados 20 anos desde a criação da Global Reporting Initiative e considerando que houve atualizações nas diretrizes a pergunta de pesquisa que se apresenta é: como estão os níveis de adoção e evolução dos relatórios de sustentabilidade das empresas listadas no ISE/Bovespa comparadas com as empresas do Brasil e do mundo que utilizam as diretrizes da GRI? O objetivo da pesquisa é verificar o nível de adoção e evolução dos relatórios de sustentabilidade da Global Reporting Initiative - GRI das empresas do ISE Bovespa comparados com as demais empresas do Brasil e do mundo, tendo como referência os relatórios GRI.

Este artigo se divide em cinco partes. A primeira, a introdução, apresenta à justificativa, problema e objetivo de pesquisa; a segunda parte contempla a fundamentação teórica da pesquisa, que discorre sobre evidenciação socioambiental, relatórios de sustentabilidade, Global Reporting Initiative, Índice de Sustentabilidade Empresarial; seguida do método de pesquisa que aborda os procedimentos de coleta e tratamento dos dados na parte três; a análise e discussão dos resultados na parte quatro, e, por fim, as considerações finais, que apresenta as principais conclusões, limitações da pesquisa e recomendações para futuros estudos.

\section{FUNDAMENTAÇÃO TEÓRICA}

O conteúdo da fundamentação teórica contempla os seguintes temas: evidenciação socioambientais; relatórios de sustentabilidade; Global Reporting Initiative (GRI) e o Índice de Sustentabilidade Empresarial (ISE) da Bovespa.

\subsection{Evidenciação socioambiental}

No ambiente das organizações a imagem dessas empresas tem se tornado preponderante junto a seus stakeholders (CORREA et. al, 2012). As transformações sociais e ambientais, que o mundo corporativo passa, sinalizam uma necessidade proeminente de reconhecimento junto à comunidade de ações de transparência nos negócios, e os relatórios de sustentabilidade são a principal ferramenta de comunicação do desempenho social, econômico e ambiental das organizações (PEREIRAet. al., 2015). Para Azevedo (2006), a incorporação da sustentabilidade no universo empresarial está condicionada a vários aspectos como as crenças do próprio dirigente da empresa, a mobilização da sociedade, a influência do mercado nacional e internacional, a atuação do setor público, a pressão de organismos internacionais, entre inúmeros outros fatores de ordem conjuntural. Devido a necessidade das empresas demonstrarem a preocupação com os recursos naturais e os efeitos que suas atividades exercem sobre o meio ambiente, o comprometimento com a transparência e responsabilidade socioambiental tornou-se imprescindível para evitar desperdícios e degradações (DOMENICO; TORMEM; MAZZIONI, 2017). 
Já Sachs (1997) apresenta um conceito evolutivo e dinâmico, que apresenta cinco dimensões, sendo: sustentabilidade social, econômica, ecológica, geográfica e cultural.

O progressivo acesso à informação aproximou investidores, empresas e sociedade; paralelamente, a conscientização ambiental aumentou com o processo de globalização (MADALENA et. al., 2016). Este ambiente induz a novos desafios, exigindo uma postura ética, valores culturais, comportamento ambiental, produtos mais limpos e legislação cada vez mais rigorosa em relação às questões sociais e ambientais (CLARO; CLARO, 2014). O público passou a expressar suas preocupações com o comportamento social das empresas, exigindo maior envolvimento delas na solução dos problemas, questionando o papel das empresas na sociedade (ALIGLERI et. al 2009). Por isso a necessidade de socializar as ações sustentáveis desenvolvidas na empresa, que garantam um diálogo transparente por meio de balanços sociais, relatórios de sustentabilidade e indicadores, consolida os mecanismos de divulgação (TONOLLI et. al, 2017). Para Madalena et. al. (2019), surge então, a necessidade de divulgar informações relevantes ao impacto social, ambiental e econômico das empresas.

\subsection{Relatórios de sustentabilidade}

O termo sustentável seria a ideia de usar os recursos naturais de maneira consciente, que não afete negativamente o meio ambiente, evitando comprometer as futuras gerações (ALMEIDA et. $a l ., 2017)$. Na década de 70 o conceito de sustentabilidade teve grande repercussão na sociedade por sua relação com crescimento econômico e o meio ambiente. Sob essa égide ocorreu a Conferência de Estocolmo em 1972, com o primeiro alerta sobre os riscos ambientais e o papel das organizações neste contexto.

Ao ser publicado o Relatório de Bruntland (1987), "Nosso Futuro Comum”, o conceito de desenvolvimento sustentável toma um discurso público. De acordo com Mattarozzi \& Trunkl (2008), foi o primeiro passo para a incorporação da sustentabilidade aos negócios, e a determinação de fazêlo integrando os critérios socioambientais de forma estratégica na organização para fazer parte da cultura do país. E, na década de 90, organizações foram criadas para definir padrões e monitorar o comportamento das empresas, quando surgem os primeiros modelos de relatórios de sustentabilidade.

Conforme a visão da Global Reporting Initiative (GRI), a economia global sustentável levará as organizações a medir seus desempenhos e impactos econômicos, ambientais, sociais de maneira responsável e transparente, para que haja eficácia nas relações com os stakeholders, nas decisões sobre investimento e em outras relações do mercado. A missão da GRI é satisfazer a necessidade, oferecendo uma estrutura confiável para a elaboração de relatórios sustentabilidade (ALMEIDA et. al. 2017).

As organizações, ao consolidar seus relatórios, têm nas mãos um instrumento que possibilita consolidar um processo de melhoria sistêmica, além de dialogar com a sociedade sua intenção de transparência na busca do desenvolvimento sustentável (CORREA et. al. 2012; MADALENA et. al, 2016; LARA; OLIVEIRA, 2017). Os relatórios registram a responsabilidade social e ambiental, geram transparência na execução de suas atividades, demonstram maior envolvimento da empresa com a sociedade e possibilitam benefícios para a comunidade em geral e para os recursos naturais, que estão sendo preservados (MAZZIONI et al., 2010). A adequada evidenciação das práticas sociais e ambientais pode agregar valor às organizações, pois, além de promover a transparência das informações, possibilita aumentar a comunicação e reduzir a discrepância com as suas contrapartes (DOMENICO; TORMEM; MAZZIONI, 2017). Portanto os relatórios de sustentabilidade são documentos descritivos de uma realidade e devem oferecer informações de forma integral da situação encontrada. 
Elaborar relatórios de sustentabilidade é a prática de medir, divulgar e prestar contas para stakeholders internos e externos do desempenho organizacional visando o desenvolvimento sustentável (GRI, 2011). Para Walt (2018), na forma atual, o relato sustentável de uma organização é uma consolidação da comunicação sobre questões econômicas, ambientais e sociais que podem estar em um relatório independente ou que podem fazer parte de um relatório anual.

A evidenciação é uma importante ferramenta de gestão de controle, e possibilita rever e implantar ações de adequações ou ajustes sempre que necessário. Existem organizações que adotam relatórios com modelos próprios, outras organizações adotam modelos consolidados que definem exigibilidades próprias que servem para evidenciar as ações socioambientais implementadas, estabelecendo padrões de documentos ambientais, além de contemplar uma estratégia organizacional (ROSA et al., 2011).

Os Indicadores Ethos são uma ferramenta de gestão que visa apoiar as empresas na incorporação da sustentabilidade e da responsabilidade social empresarial (RSE) em suas estratégias de negócio, de modo que esse venha a ser sustentável e responsável (ETHOS, 2018) Trabalha com um questionário que permite o autodiagnostico da gestão da empresa, que proporciona a obtenção de relatórios, através dos quais se torna possível planejar a gestão da responsabilidade social empresarial e a sustentabilidade.

A atual geração dos Indicadores Ethos, após 20 anos de sua implementação, segundo informações do site está continuamente aprimorada. Apresenta uma nova abordagem para a gestão das empresas e procura integrar os princípios e comportamentos da RSE com os objetivos para a sustentabilidade, baseando-se num conceito de negócios sustentáveis e responsáveis ainda em desenvolvimento. Além de ter maior integração com as diretrizes de relatórios de sustentabilidade da Global Reporting Initiative (GRI), com a Norma de Responsabilidade Social ABNT NBR ISO 26000e outras iniciativas (ETHOS, 2018).

Relatório de sustentabilidade é um termo amplo, considerado sinônimo de outros relatórios, cujo objetivo é uma descrição dos impactos econômicos, ambientais e sociais de uma empresa. Azevedo (2006) sugere que, seja sob a forma de balanços sociais, de relatórios socioambientais, ou ainda de relatórios de sustentabilidade, há no Brasil um número cada vez maior de empresas que divulgam publicamente suas ações sociais e ambientais.

A Global Reporting Initiative nos seus relatórios oferece às empresas a possibilidade de publicarem seus relatórios de sustentabilidade em um padrão global, em um modelo organizado de indicadores e informações (FERREIRA-QUILICE; CALDANA, 2015). Para Leite Filho, Prates e Guimaraes (2009), essa publicação oferece benefícios gerenciais para as empresas, visto que a GRI é apreciada pelos investidores e considerada ferramenta indispensável para as empresas que negociam seus títulos no mercado mundial. A quarta geração das Diretrizes da GRI, G4, foi lançada em maio 2013, revisado para aprimorar e refletir tendências atuais e futuras importantes nos relatórios de sustentabilidade.

A missão da GRI é oferecer uma estrutura confiável para a elaboração de relatórios sustentabilidade (ALMEIDA et. al, 2017), essa estrutura proporciona a base dos relatórios da GRI, o que o torna um grande atributo (CORREA et al, 2012). Sendo que as diretrizes para a elaboração de relatórios de sustentabilidade compreendem os princípios, as orientações e os indicadores de desempenho (GRI, 2011).

\subsection{Global Reporting Initiative}

Criado em 1997, a GRI é uma organização internacional com a missão de desenvolver e disseminar relatórios de sustentabilidade (DOMENICO; TORMEM; MAZZIONI, 2017). Em 1999 foram elaboradas as Diretrizes para Relatório de Sustentabilidade da GRI, lançadas em 2001 (CAMPOS 
et al., 2013). Em 2002 houve a primeira atualização, publicada em 2004 no Brasil, e outra atualização em 2006, chamada de G3, referenciando a terceira geração de indicadores. O lançamento da GRI G3 representou uma grande evolução para os relatórios de sustentabilidade, pela forma que foi revisado, que envolveu mais de 4000 pessoas de todo o mundo para o seu aperfeiçoamento (CORREA et al. 2012). Para assegurar alto grau de qualidade técnica, credibilidade e relevância, a estrutura de relatórios de sustentabilidade da GRI é desenvolvida e continuamente melhorada por meio do engajamento de diversos stakeholder, que envolve organizações relatoras e especialistas que, juntos, desenvolvem e revisam o conteúdo da estrutura do relatório (GRI, 2011).

Para Scandelari \& Cunha (2013), o relatório GRI aborda a sustentabilidade, nas suas diretrizes, buscando um equilíbrio entre o desempenho econômico, social e ambiental, o chamado triple botton line. As diretrizes contêm princípios de relatório e orientações, assim como um modelo de conteúdo do relatório - incluindo indicadores - que delineia uma estrutura de divulgação que as organizações podem adotar de forma voluntária, flexível e progressiva (GRI, 2011). As diretrizes são o pilar que se apoiam todas as outras orientações para a elaboração de relatórios e apresentam o conteúdo considerado relevante para organizações de qualquer porte, setor ou localidade (CORREA et al, 2012).

Segundo Domenico, Tormem \& Mazzioni (2017), os relatórios funcionam como mecanismo de avaliação das práticas desenvolvidas na sociedade e o Global Reporting Initiative, sendo uma instituição independente com o propósito de desenvolver e disseminar diretrizes para os relatórios de sustentabilidade globalmente aplicáveis (VERÍSSIMO, 2011), suas diretrizes são atualizadas a cada dois anos, em revisões periódicas, para se adequar a mudanças e novas necessidades. As diretrizes para construção dos relatórios de sustentabilidade, oferecem condições de elaboração, que podem ser usadas por organizações de todos os tamanhos, setores e localidades (GRI, 2011).

Ao se construir uma linha do tempo dos principais eventos que promoveram a evolução do relatório Global Reporting Initiative, pode-se identificar a seguinte evolução: no ano de 1997 - GRI tendo sido criada nessa ocasião na cidade de Boston, com a missão de desenvolver e disseminar globalmente suas diretrizes, para elaboração de relatórios de sustentabilidade.

No ano 2000 ocorrendo o lançamento e desenvolvida dentro de um processo de engajamento voluntário de representantes do setor empresarial.

A segunda geração de orientações ocorreu no ano de 2002 - sua sede foi estabelecida em Amsterdã e o PNUMA passou a ser colaborador. Em 2006, ocorreu o lançamento da terceira geração de diretrizes - GRI G3, que teve participantes especialistas de empresas e sociedade civil.

Em 2007, houve o lançamento no Brasil nas diretrizes. De muita relevância a atualização de 2011, sendo que concluiu o G3 e promoveu uma orientação sobre desempenhos relacionados a questões de gênero, comunidade e direitos humanos.

Essa evolução das exigibilidades no relatório promove um alinhamento a realidade e evolução sob o aspecto de sustentabilidade que deve permear a gestão das empresas, que ainda promoveu mais recentemente, em 2016, que tratou de ajustes no padrão dos relatórios, e em 2017, que evidenciou relatórios de negócios de forma compacta, sempre na busca do desenvolvimento de diretrizes mais consistentes e confiáveis.

Duas décadas depois de ser pioneira no processo de relato de sustentabilidade em 1997, a GRI é a mais conhecida criadora de padrões de sustentabilidade do mundo, com evolução significativa na estrutura dos relatórios de sustentabilidade, incorporando novos tópicos e melhores práticas à medida que surgem (GRI, 2017). 
Segundo o site da GRI ao longo desses anos, a GRI promoveu um impacto na economia global, meio ambiente e sociedade, ajudando mais de 7200 organizações a usar a estrutura GRI de relatórios para divulgar seus impactos de sustentabilidade, bem como capacitam quase 30.000 profissionais para sistematizar a elaboração do relatório de sustentabilidade (GRI, 2017).

A análise detalhada da estrutura da GRI mostra que o conjunto de diretrizes e indicadores proporciona a comparabilidade, credibilidade, periodicidade e legitimidade da informação na comunicação do desempenho social, ambiental e econômico das organizações (RIBEIRO; GOMES; SOUZA, 2011), para que haja eficácia nas relações com os stakeholders, nas decisões sobre investimento e em outras relações do mercado (ALMEIDA et. al., 2017).

A GRI oferece uma estrutura confiável para a elaboração de relatórios sustentabilidade, por isso seus indicadores de desempenho estão organizados em categorias, social, ambiental e econômica. Os indicadores sociais são subdivididos nas seguintes categorias: práticas trabalhistas, direitos humanos, sociedade e responsabilidade pelo produto.

Para cumprir sua missão, a GRI identificou quatro áreas de foco para os próximos anos: Crie padrões e orientações para promover o desenvolvimento sustentável: forneça ao mercado liderança em divulgações consistentes de sustentabilidade, incluindo o envolvimento com as partes interessadas em questões emergentes de sustentabilidade; Harmonize o cenário da sustentabilidade: faça da GRI o centro central de estruturas e iniciativas de relatórios de sustentabilidade e selecione oportunidades de colaboração e parceria que atendam à visão e missão da GRI; Lidere relatórios de sustentabilidade eficientes e eficazes: melhore a qualidade das divulgações feitas com os padrões da GRI, reduzindo a carga de relatórios e explorando os processos de relatórios que auxiliam na tomada de decisões; Impulsione o uso efetivo das informações de sustentabilidade para melhorar o desempenho: trabalhe com formuladores de políticas, bolsas de valores, reguladores e investidores para promover a transparência e permitir relatórios efetivos. (GRI, 2020).

A GRI apresentou os primeiros padrões globais para relatórios de sustentabilidade, com uma estrutura modular e interrelacionada e representam as melhores práticas globais para relatar uma variedade de impactos econômicos, ambientais e sociais (GRI, 2020).

A prática de divulgar informações de sustentabilidade inspira a responsabilidade, ajuda a identificar e gerenciar riscos e permite que as organizações aproveitem novas oportunidades. Os relatórios com os Padrões da GRI apoiam empresas, públicas e privadas, grandes e pequenas, protegem o meio ambiente e melhoram a sociedade, enquanto, ao mesmo tempo, prosperam economicamente, melhorando a governança e as relações com as partes interessadas, melhorando a reputação e construindo confiança (GRI, 2020). A organização deverá relatar os indicadores essenciais, a menos que eles demonstrem não estar alinhados aos princípios de relatório da GRI. Os indicadores adicionais representam práticas emergentes ou tratam de temas que podem ser relevantes para algumas organizações, mas não para outras (GRI, 2011).

Os indicadores propostos pelo GRI 2009, em número de 79, envolvem questões sobre desempenho econômico, social e ambiental. Os nove indicadores de desempenho econômico envolvem aspectos sobre desempenho econômico geral (4), presença de mercado (3) e impactos econômicos indiretos (2). os 40 indicadores de desempenho social contemplam práticas de mão de obra e trabalho 
decente (14), direitos humanos (9) desempenho em relação à sociedade (8) e responsabilidade pelo produto (9). Enquanto os 30 indicadores de desempenho ambiental abordam aspectos sobre consumo de materiais (2); energia (5); água (3); biodiversidade (5); emissões, efluentes e resíduos (10); produtos e serviços (2); conformidade (1); transporte (1) e geral, que contempla gastos e investimentos em proteção ambiental (1). os suplementos setoriais complementam as diretrizes com interpretações e orientações sobre seu uso, em determinado setor e incluem indicadores de desempenho específicos do setor, não em substituição a elas (PEREIRA; FARIA; SOUZA, 2009).

As principais mudanças nos indicadores G4, (GRI, 2018): materialidade - Princípio: o relatório deve abordar Aspectos que: Reflitam os impactos econômicos, ambientais e sociais significativos da organização; ou Possam influenciar, substantivamente, as avaliações e decisões de stakeholder; Inclusão de stakeholders - Princípio: A organização deve identificar seus stakeholders e explicar no relatório as medidas que adotou para responder às expectativas e interesses razoáveis dessas partes; Novos requisitos de divulgação de informação sobre a cadeia de fornecedores, em cada pilar (Econômico, Ambiental e Social): as organizações devem reportar informação sobre a gestão das suas cadeias de fornecedores, quando este tema é considerado material; Contexto da sustentabilidade - Princípio: O relatório deve descrever o desempenho da organização no contexto mais amplo da sustentabilidade; Novos requisitos de divulgação de informação sobre Governance, Remuneração, Ética e Integridade; Maior foco nas Formas de Gestão, por via de uma uniformização do seu formato de reporte; Alteração dos indicadores de Anticorrupção e Emissões de GEE (alinhados com o GHG Protocol - âmbitos 1, 2 e 3); Substituição dos níveis de aplicação por duas opções de reporting "De acordo": Essencial e Abrangente; Nova tabela GRI, com uma coluna para a verificação externa.

A Global Reporting Initiative (GRI) lançou a quarta versão das suas diretrizes para elaboração de relatórios de sustentabilidade, no final de maio de 2013. Comparativamente com a versão anterior, G3 de 2006, as diretrizes G4 têm a materialidade como principal critério para a sua implementação. Quando finalizado o relatório de sustentabilidade, deverá ser declarado pelos relatores o nível de aplicação da estrutura de relatório GRI. Essa declaração fornece aos relatores, uma visão ou possibilidades da aplicação da estrutura do relatório GRI ao longo do tempo e aos usuários transparência e clareza sobre até que ponto foi aplicado a estrutura do relatório na sua elaboração.

A empresa ao declarar o nível de aplicação, remete a uma comunicação clara e transparentes de quais elementos da estrutura de relatórios da GRI foram aplicados na elaboração do relatório, os relatores iniciantes utilizam - nível C, os relatores intermediários - nível B, e os relatores avançados - nível A. Os critérios de relato encontrados em cada um dos níveis indicam a evolução da aplicação ou cobertura da estrutura de relatórios da GRI. A organização poderá autodeclarar um ponto a mais (+) em cada nível (por exemplo, $\mathrm{C}+, \mathrm{B}+, \mathrm{A}+$ ), caso tenha sido utilizada verificação externa (GRI, 2011).

A transparência na construção do relatório deverá evidenciar: clareza, exatidão, periodicidade, comparabilidade e confiabilidade. A publicidade das informações deverá ser coerente com esses princípios, que orientam a elaboração, para assegurar a qualidade das informações relatadas, incluindo sua apresentação. Os principais produtos da GRI são: os Padrões de Relatórios de Sustentabilidade, disponibilizados como um bem público gratuito. Eles foram desenvolvidos continuamente ao longo de 20 anos e representam as melhores práticas globais para relatar questões econômicas, ambientais e sociais. (GRI, 2020). As organizações ao elaborarem o relatório tem um documento que apresenta as práticas do que realizaram e que poderá servir de orientação para implantar e redefinir melhores práticas. 
O Índice de Sustentabilidade Empresarial (ISE) busca criar um ambiente de investimento compatível com as demandas de desenvolvimento sustentável da sociedade contemporânea e estimular a responsabilidade ética das corporações, (ALMEIDA et. al., 2017) e divulgar relatórios de sustentabilidade de acordo com o modelo da GRI é uma maneira das empresas que compõem o ISE evidenciar de forma transparente às partes interessadas seus projetos em ações socioambientais (CORREA et. al, 2012).

\section{4 Índice de Sustentabilidade Empresarial (ISE)}

O Índice de Sustentabilidade Empresarial (ISE), iniciado em 2005, foi originalmente financiado pela International Finance Corporation (IFC), braço financeiro do Banco Mundial, e o $4^{\circ}$ (quarto) índice de sustentabilidade a ser lançado no mundo (ALMEIDA et. al., 2017). O ISE é uma ferramenta para análise comparativa da performance das empresas listadas na B3 sob o aspecto da sustentabilidade corporativa, baseada em eficiência econômica, equilíbrio ambiental, justiça social e governança corporativa. Também amplia o entendimento sobre empresas e grupos comprometidos com a sustentabilidade, diferenciando-os em termos de qualidade, nível de compromisso com o desenvolvimento sustentável, equidade, transparência e prestação de contas, natureza do produto, além do desempenho empresarial nas dimensões econômico-financeiro, social, ambiental e de mudanças climáticas (BM \& FBOVESPA, 2018).

O ISE estabeleceu novas relações entre a empresa e a sociedade, construídas por meio da ética, reputação e do comportamento sustentável, evidenciado pelas empresas em seus relatórios. Para Domenico, Tormem \& Mazzioni (2017) a responsabilidade social e ambiental é entendida como um conjunto de ações voltadas para a estratégia gerencial das empresas, visando ao seu comprometimento com os recursos naturais e ao mesmo tempo contribuindo com o desenvolvimento econômico, e se torna visível esse comprometimento em seus relatórios.

O ISE tem por objetivo promover boas práticas socioambientais para as organizações brasileiras e foi formulado utilizando o conceito do Triple Botton Line (TBL) que avalia, de forma integrada, as dimensões econômico-financeiras, sociais e ambientais das empresas (LINS; SILVA, 2009). O ISE objetiva comparar o desempenho de empresas listadas na BM\&FBOVESPA sob os aspectos da sustentabilidade (DI AGUSTINI, 2011) e de acordo com a BM\&FBOVESPA tem como objetivo de ser o indicador do desempenho médio das cotações dos ativos de empresas com reconhecido comprometimento com a sustentabilidade empresarial (DINIZ; CALLADO, 2017).

O ISE serve como uma referência para indicar quais ações, dentre as negociadas pela Bovespa, são mais seguras em longo prazo, e tendem a representar menor risco ao investimento (LINS; SILVA, 2009), levando o investidor a reconhecer as empresas mais seguras para investir.

\section{PROCEDIMENTOS METODOLÓGICOS}

Quanto à abordagem a pesquisa foi qualitativa, segundo Creswell (2010) os procedimentos qualitativos baseiam-se em dados de textos e imagens, e se valem de diferentes estratégias de investigação.

Em relação aos procedimentos técnicos, a referida pesquisa será do tipo bibliográfico e documental. Acevedo \& Nohara (2007) afirmam que o levantamento bibliográfico consiste na busca de estudos anteriores que já foram produzidos por outros cientistas e que geralmente são publicados em livros ou artigos científicos. Em relação à pesquisa documental, Gil (1995) afirma que se vale de 
materiais que não receberam ainda um tratamento analítico, ou que ainda podem ser reelaborados de acordo com os objetivos da pesquisa. Pretende-se realizar uma análise documental dos relatórios de sustentabilidade de empresas que declaram em conformidade as diretrizes GRI.

O universo da pesquisa foram as duzentas e sessenta e três empresas brasileiras que participam do ISE da Bovespa em 2016, e 31 delas que relatam seus relatórios de sustentabilidade referenciados pela GRI.

\subsection{Procedimentos de coleta dos dados}

A coleta de dados foi realizada no Report List GRI anos entres 1999 a 2018, disponível no site da GRI, com o objetivo de verificar a evolução desses relatórios nas empresas que relatam no modelo no mundo, no Brasil e no ISE Bovespa. Sendo que durante esses 20 anos algumas empresas deixaram de publicar seus relatórios no site da GRI, bem como nos sites da própria organização.

\subsection{Procedimentos de tratamento e análise dos dados}

O tratamento dos dados foi realizado por meio do software Excel (2007) utilizando a estatística descritiva e na análise foram considerados os seguintes tópicos: a evolução das empresas no mundo que adotam o modelo da GRI; a adoção do relatório no Brasil; o crescimento evolutivo no Índice de Sustentabilidade da Bovespa; e os níveis de aplicação adotados pelas empresas.

\section{ANÁLISE E DISCUSSÃO DOS RESULTADOS}

A revisão da literatura evidencia que a publicação de relatórios de sustentabilidade caracterizase como boas práticas ambientais. $\mathrm{O}$ estudo mostra que as empresas pesquisadas, passaram por uma evolução nos níveis de aplicação da GRI.

A pesquisa revela primeiramente (Gráfico 1) um crescimento do número de empresas que relatam usando o modelo da GRI no mundo, sendo que no ano de 1999, somente 11 empresas faziam uso do modelo, em 2007 foram 711, em 2011 foram 1940, chegando em 2016 com 3880 empresas. A utilização do modelo de relatório GRI corresponde a um crescimento ascendente, nos 19 anos de seu uso no mundo, uma vez ainda não ter disponíveis os relatórios na íntegra do ano 2017, o que evidencia a legitimação do modelo no mundo.

Gráfico 1- Empresas no Mundo

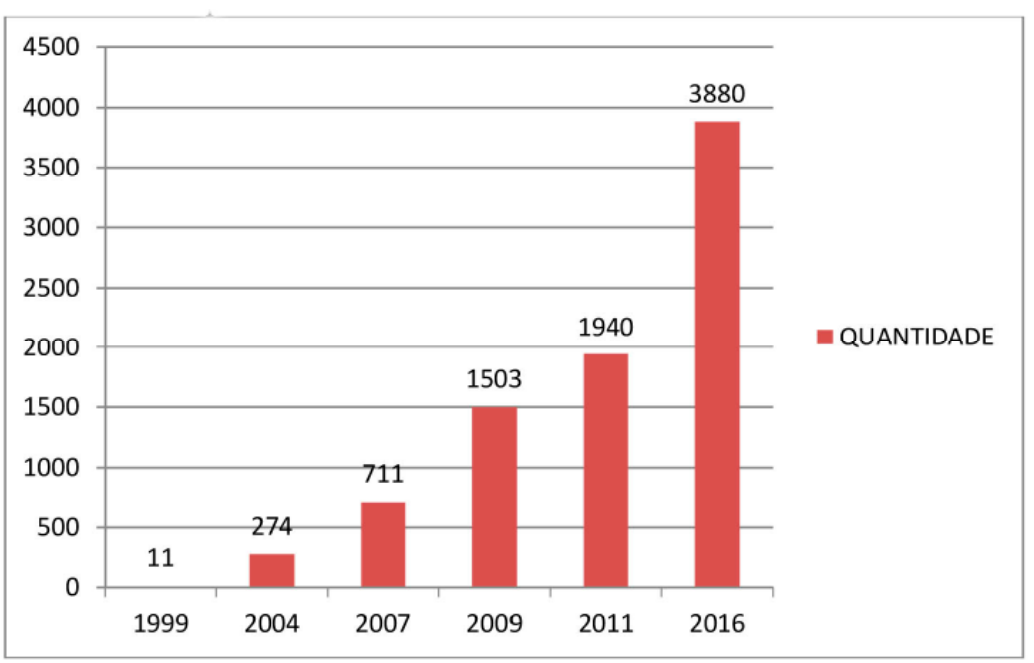

Fonte: Dados da pesquisa

\section{3}


A escolha do modelo do relatório por ser uma decisão voluntária, acaba fazendo com que as empresas optem por modelos consolidados. Para Clarkson et al. (2008) afirmam que as decisões voluntárias das empresas para preparar um relatório de acordo com o modelo da GRI, irá resultar em divulgação de um relatório que apresenta a indicação de um bom desempenho ambiental.

Já no Brasil o uso do modelo GRI corresponde a um crescimento entre os anos de 1999 a 2016, como mostra o Gráfico 2. O relato por meio dessa estrutura está evoluindo de maneira significativa, mostrando que as empresas no Brasil em 2016 foram 263 empresas que relataram usando o modelo, e estão acompanhando a tendência internacional na evidenciação das informações de sustentabilidade.

Gráfico 2- Empresas no Brasil

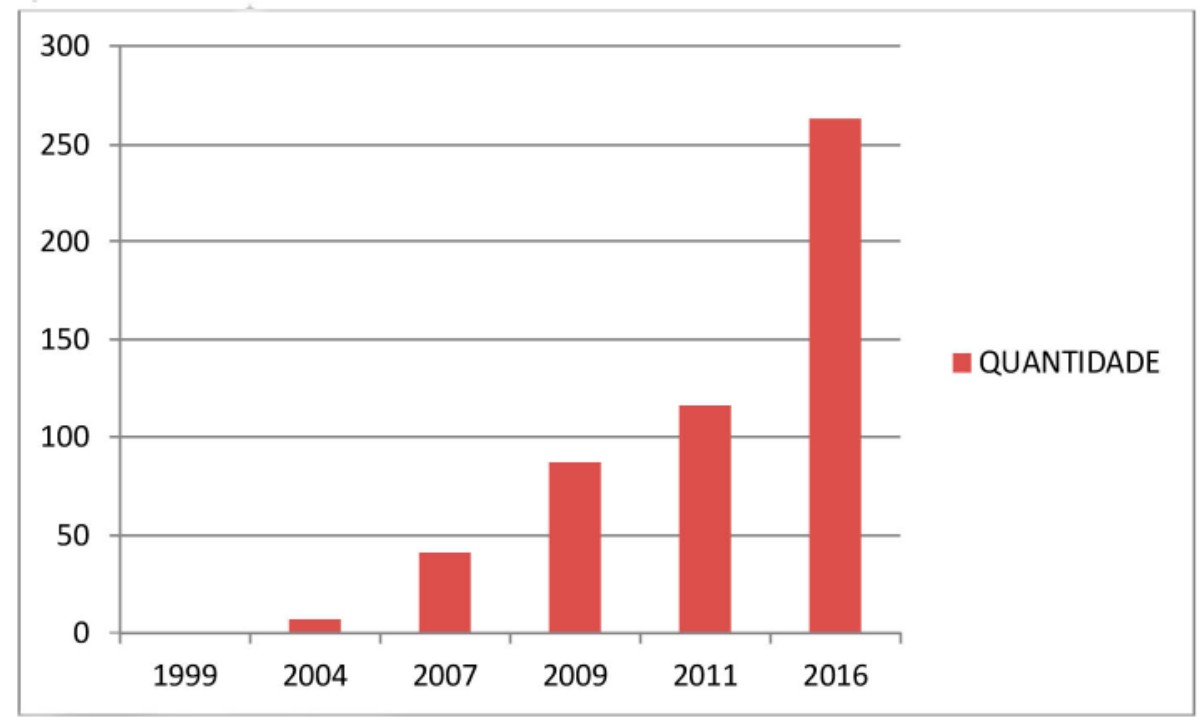

Fonte: Dados da pesquisa

As empresas do ISE da BMF\&BOVESPA também seguiram a mesma tendência na adoção ao modelo da GRI com crescimento significativo no período de 2005 a 2010, conforme Gráfico 3. Tal crescimento é decorrente do fato de que as empresas da carteira do ISE, as quais estão entre as emissoras das 200 ações mais líquidas, adequaram o questionário do ISE (BMF\&BOVESPA, 2011) aos indicadores de sustentabilidade.

Gráfico 3- Empresas nacionais atuantes no ISE

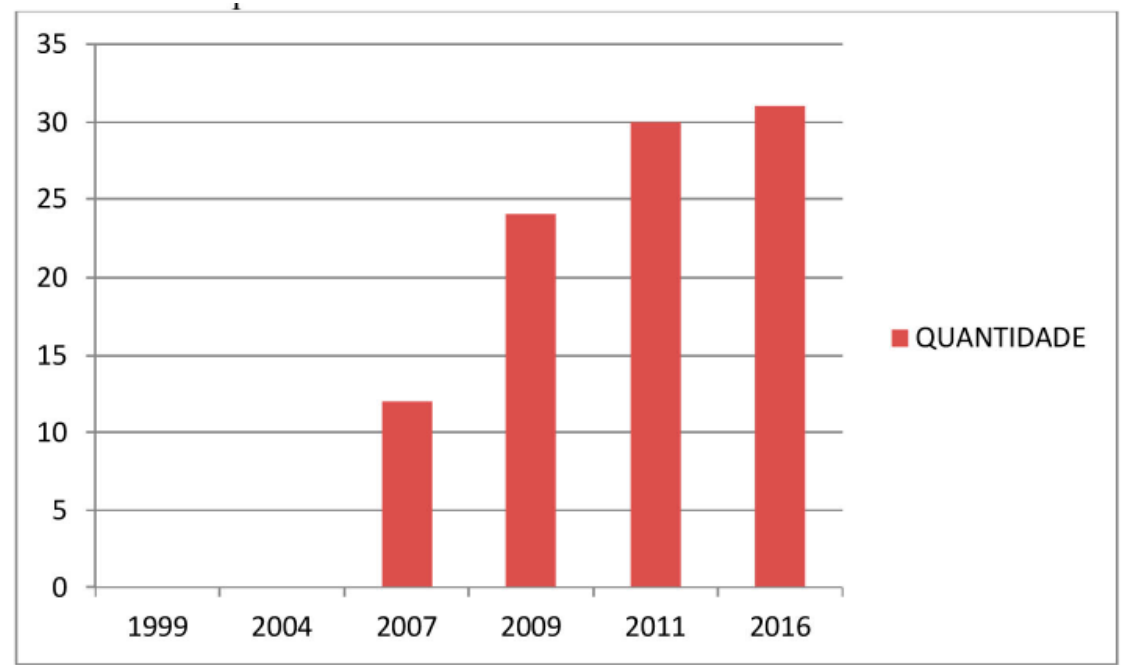

Fonte: Dados da pesquisa 
O Gráfico 3 mostra a adoção das empresas do ISE ao modelo de relatório de sustentabilidade da GRI. Pode-se considerar muito significativo a implementação ao modelo, uma vez que o crescimento apresenta uma evolução de doze empresas em 2007 para 31 empresas em 2016. Percentualmente a adoção por ano apresenta de forma gradativa e ascendente, legitimando o modelo de relatório GRI, junto às empresas do ISE/Bovespa.

De acordo com site da Global Reporting Initiative (2018), no ano de 2016 foram publicados, no mundo, cerca de 5695 relatórios de sustentabilidade, e no Brasil 263 relatórios, o que corresponde aproximadamente $6 \%$ do total de relatórios da GRI no mundo.

Quadro 2 - Níveis dos relatórios do com verificação em uso no mundo

\begin{tabular}{|l|c|c|c|c|c|c|c|c|}
\hline Ano & $\begin{array}{c}\text { GRI } \\
\text { G4 }\end{array}$ & $\begin{array}{c}\text { Citing } \\
\text { GRI }\end{array}$ & $\begin{array}{c}\text { GRI } \\
\text { Reference }\end{array}$ & $\begin{array}{c}\text { NON } \\
\text { GRI }\end{array}$ & $\begin{array}{c}\text { GRI } \\
\text { G3 }\end{array}$ & $\begin{array}{c}\text { GRI G3 } \\
\text { A }\end{array}$ & $\begin{array}{c}\text { GRI } \\
\text { G2 }\end{array}$ & $\begin{array}{c}\text { GRI } \\
\text { GA }\end{array}$ \\
\hline $\mathbf{1 9 9 9}$ & & & & & & & 277 & 1 \\
\hline $\mathbf{2 0 0 4}$ & & & & & 1 & 573 & 144 & \\
\hline $\mathbf{2 0 0 7}$ & & & 2 & 1 & & & 2 & \\
\hline $\mathbf{2 0 0 9}$ & & & 4 & & 1537 & & & \\
\hline $\mathbf{2 0 1 1}$ & & & 8 & 1 & 1722 & & & \\
\hline $\mathbf{2 0 1 6}$ & 3235 & 639 & & 6 & 1815 & 342 & & \\
\hline
\end{tabular}

Fonte: Dados da pesquisa

O Quadro 2 apresenta os níveis de relatórios em uso no mundo e o que se identifica é que no ano de 2016 os relatórios no modelo GRI G4 representou 54\% do modelo adotado pelas empresas o que evidencia adoção do modelo de relatório mais completo. Contudo, é possível perceber que à evolução dos níveis ocorre de forma gradativa em todos os níveis, demonstrando que as empresas ao preencherem seus relatórios, percorrem o caminho dessa evolução de forma gradual.

O Quadro 3 mostra a evolução do Relatório da GRI e dos níveis de aplicação no Brasil, em 2016 pode ser verificado que ouve uma adoção significativa no modelo GRI G4, representando 74\% dos relatórios, evidenciando uma evolução das empresas que informam no relatório mais completo.

Quadro 3- Níveis dos relatórios com verificação em uso no Brasil

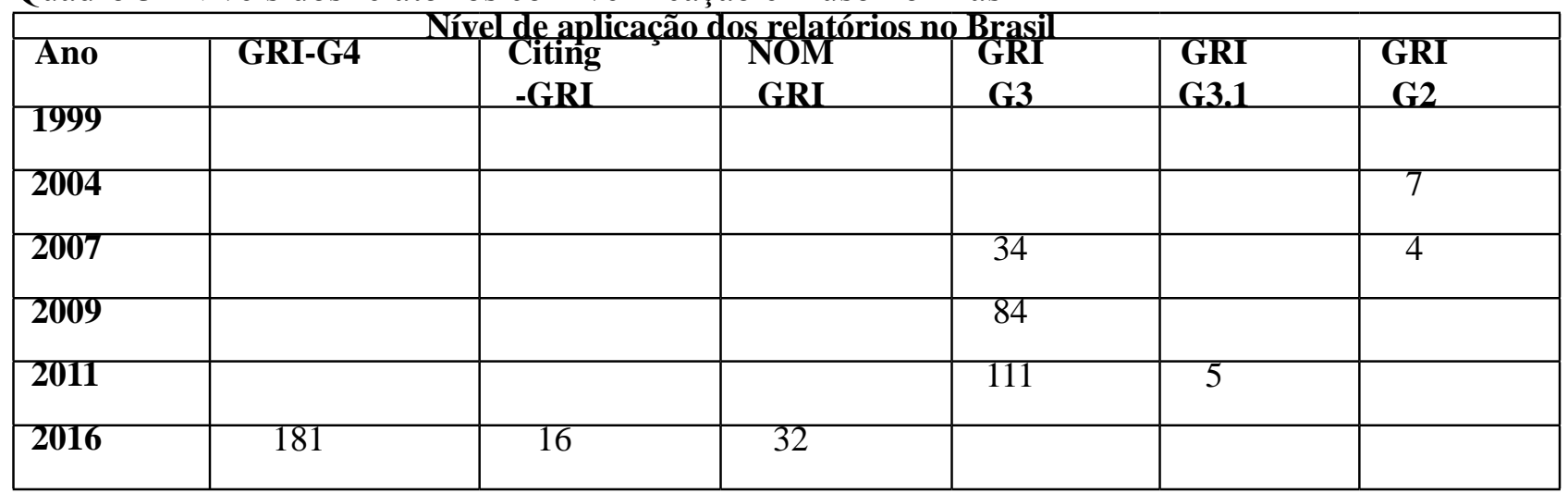

Fonte: Dados da pesquisa

Estudo feito por Basseto (2010) sugere que a GRI é um modelo de evidenciação que está limitado aos aspectos qualitativos, uma vez que as próprias diretrizes não avançaram ainda para um 
grau de detalhamento e de comprovação efetiva de resultados que possam ser mensuráveis. Esse resultado pode incentivar um aperfeiçoamento no modelo, uma vez que está em processo e adequação permanente, o que é verificado nas mudanças do modelo desde que foi criado (CORREA et. al., 2012) O estudo de Madalena et. al. (2012) identificou uma melhoria na divulgação socioambiental. Uma vez que os impactos relacionados ao assunto vêm sendo cada vez mais escrutinados, na medida em que a informação é difundida e seu entendimento é maior entre a população, o que ficou confirmado nesse estudo.

Apesar da evolução no aumento da adoção de relatórios no modelo da GRI, evidenciado nesse estudo, Makela afirma em seu estudo em 2018 que, apesar do aumento do número de empresas que adotam o modelo, este ainda pode ser considerado inferior se comparado a quantidade total de empresas existentes. Ao fornecer diretrizes para relatórios, o GRI visa promover a transparência e a responsabilidade organizacional, bem como o engajamento das partes interessadas (VIGNEAU et al., 2015). Por isso a importância de mais empresas adotarem o GRI, o que promoveria maior uniformidade com informações e qualidade dos relatórios, com o desempenho real da Responsabilidade Social Corporativa.

\section{CONCLUSÃO}

O objetivo do estudo foi verificar o nível de adoção e evolução dos relatórios de sustentabilidade da Global Reporting Initiative- GRI nas empresas, e seus níveis de aplicação das empresas do ISE comparados com as demais empresas do Brasil e do mundo.

Os principais resultados mostram que houve uma evolução na adoção do modelo Global Reporting Initiative no mundo, bem como uma adoção das empresas a níveis crescentes de evolução do relatório de nível G1 para o nível G4. No Brasil está adoção ao relatório também vem evoluindo, tanto na implantação como na evolução dos níveis dos relatórios, bem como das empresas que relatam na ISE. Confirmando a consolidação e a legitimação da metodologia da GRI de divulgação de relatórios de sustentabilidade.

As Diretrizes da GRI G4 representam um código de conduta e um padrão de desempenho, vistos com materialidade, evidenciado nas 3235 empresas que usam esse nível no mundo, dos quais $6 \%$ são empresas brasileiras, propiciando assim maior credibilidade das informações socioambientais aos seus stakeholders.

A GRI tem suas bases de relatórios na quarta geração do modelo, GRI-G4, o que mostra um empenho na melhoria contínua dos indicadores e sua adoção por diferentes países. Os resultados da pesquisa mostram a evolução permanente dos relatórios, na busca do nível mais aprimorado de relatório de sustentabilidade, e com adoção significativa no Brasil, o que legitima o modelo de relatório de sustentabilidade da Global Reporting Initiative.

Como limitação, este estudo se deparou com a falta de informações das empresas que ainda não postaram seus relatórios de 2017, o que impediu o recorte temporal dos 20 anos de GRI no mundo. Sugere-se para futuros estudos atualizar as informações com todas as empresas do ano de 2017 o que configuraria uma abrangência total das empresas durante o período dos 20 anos de GRI no mundo e no Brasil. 


\section{REFERÊNCIAS}

ACEVEDO, C. R.; NOHARA, J. J. Monografia no curso de administração: guia completo de conteúdo e forma. São Paulo: Atlas, 2007.

ALMEIDA, F. O bom negócio da sustentabilidade. Rio de Janeiro: Nova Fronteira, 2002.

ALMEIDA J. L.; NASCIMENTO JUNIOR, R.; COSTA, E. J. A. Práticas de sustentabilidade corporativa no Brasil: análise das instituições financeiras integrantes do índice de sustentabilidade empresarial. Revista Gestão e Desenvolvimento, Novo Hamburgo, RS, v. 14, n.1, p.84-99, jan./ jun.2017.

AZEVEDO, A. L. V. 2006. Indicadores de sustentabilidade empresarial no Brasil: uma avaliação do Relatório do CEBDS. Revista Iberoamericana de Economia Ecológica, v. 5, p. 75-93, 2006. Disponível em: <http://www.redibec.org/IVO/rev5_>. Acesso em: 26 mar. 2011.

BASSETTO, L. I. A incorporação da responsabilidade social e sustentabilidade: um estudo baseado no relatório de gestão 2005 da companhia paranaense de energia - COPEL. Gestão \& Produção, São Carlos, SP, v. 17, n. 3, p. 639-651, 2010.

BM\&FBOVESPA. Índice de Sustentabilidade Empresarial. ISE- Índice de Sustentabilidade Empresarial. Disponível em: <http://www.bmfbovespa.com.br/>. Acesso em: 12 ago. 2018.

CAMPOS, L. M. de S.; SEHNEM, S.: OLIVEIRA, M. de A. S.; ROSSETTO, A. M.; COELHO, A. C. de A. L.; DALFOVO, M. S. Relatório de sustentabilidade: perfil das organizações brasileiras e estrangeiras segundo o padrão da Global Reporting Initiative. Gestão \& Produção, São Carlos, SP, v. 20, n. 4, p. 913-926, 2013.

CASTRO, F. A. R.; SIQUEIRA, J. R. M.; MACEDO, M. A. S. Análise da utilização dos indicadores essenciais da versão "g3", da global reporting initiative, nos relatórios de sustentabilidade das empresas do setor de energia elétrico sul-americano. RIC - Revista de Informação Contábil, Recife, PE, v. 4, n. 4, p. 83-102, out/dez.2010.

CLARO, P. B. de O.; CLARO, D. P. Sustentabilidade estratégica: existe retorno no longo prazo? Revista de Administração da USP, São Paulo, v. 49, n. 2, p. 291-306, 2014.

CLARKSON, P. M.; LI Y.; RICHARDSON G. D.; VASVARI F. P. Revisiting the relation between environmental performance and environmental disclosure: an empirical analysis. Accounting Organizations and Society. v, 33, n. 4-5, p. 303-327, 2008.

COMISSÃO MUNDIAL SOBRE O MEIO AMBIENTE E DESENVOLVIMENTO. Nosso Futuro em Comum. 2.ed. Rio de Janeiro: FGV, 1991. 
COElHO, C.; MACEDO, J. D. F. de; COELHO, A. L. de A. L.; SILVA, A. W. P. da; SANTOS, H. C. C. dos. Desenvolvimento sustentável no Acre: a execução orçamentária sob o enfoque da gestão ambiental. Amazônia, Organizações e Sustentabilidade, Belém, PA, v. 7, n. 1, p. 93-116, jan./jul. 2018.

CORREA R.; SOUZA, M. T. S.; RIBEIRO H.C.M; RUIZ M. S., Evolução dos Níveis Aplicação de Relatórios de Sustentabilidade (GRI) de Empresas. Sociedade, Contabilidade e Gestão, Rio de Janeiro, v.7, n. 2, jul./dez. 2012.

CRESWELL, J. W. Projeto de pesquisa: métodos qualitativo, quantitativo e misto. Porto Alegre: Artmed, 2010.

DINIZ, M. L. F.; CALLADO, A. L. C. Mensurando a sustentabilidade empresarial através do grid de sustentabilidade empresarial (GSE): um estudo em empresas do setor gráfico. Amazônia, Organizações e Sustentabilidade, Belém, PA, v. 6, n. 2, p. 105-122, ago./dez.2017.

DOMENICO, D. D.; TORMEM L.; MAZZIONI S., Nível de disclosure nos relatórios de sustentabilidade em conformidade com o global reporting initiative (GRI). Revista Catarinense da Ciência Contábil, Florianópolis, SC, v.16, n. 49, p. 84-100, set/dez. 2017.

ENGELAGE, E.; PRIOR, N. L.; BORGERT, A. Disclosure of green logistic: a study in companies listed on the business sustainability index. Amazônia, Organizações e Sustentabilidade, Belém, PA, v. 7, n. 1, p. 117-138, jan./jul. 2018.

FARIA, M. J. da. S. Tipos de divulgação da informação financeira e não financeira de responsabilidade social empresarial. Cadernos EBAPE.BR, Rio de Janeiro, v. 15, n.3, p. 1-25, 2017. Edição especial.

FERREIRA-QUILICE, T.; CALDANA, A. C. F. Aspectos negativos no modelo de reporte proposto pela GRI: a opinião das organizações que reportam. Revista de Administração da USP, São Paulo, v. 50, n. 4, p.405-415, 2015.

ETHOS. Indicadores Ethos para negócios Sustentáveis e Responsáveis. Disponível em: <https:// www3.ethos.org.br/conteudo/indicadores>. Acesso em: 10 ago. 2018.

GIL, Antonio Carlos. Métodos e técnicas de pesquisa social. São Paulo: Atlas, 1995.

GRI - Global Reporting Initiative. Diretrizes G3. Disponível em: <www.globalreporting.org> Acesso em: 14 mar. 2011.

GRI - Global Reporting Initiative. Report List. Disponível em: http://www.globalreporting.org/ ReportServices/GRIReportsList/. Acesso em: 12 ago. 2018 
GRI - Global Reporting Initiative. Home. Disponível em: http://www.globalreporting.org/Home/ AboutRFPRT.htm . Acesso em: 13 abr. 2011

GRI - Global Reporting Initiative. Diretrizes para Relatório de Sustentabilidade de GRI - 2006. Disponível em: <http://www.ethos.org.br/_Uniethos/documents/gri_g3./>. Acesso em: 10 mar. 2011.

GRI - Global Reporting Initiative. Sobre o Global Reporting Ininiative. Disponível em: https:// www.globalreporting.org/information/about-gri/gri-history/Pages/GRI's history.aspx. Acesso em: 02 ago. 2017

GRI - Global Reporting Initiative. GRI G4 Guidelines and ISO 26000:2010 How to use the GRI G4 Guidelines and ISO 26000 in conjunction. Disponível em: <https://www.globalreporting.org>. Acesso em: 25 jul.2017.

GRI - Princípios para relato modelo G4. Disponível em: https://www.globalreporting.org/ resourcelibrary/Brazilian-Portuguese-G4-Part-One.pdf. Acesso em: 10 ago.2018.

GRI - Global Reporting Initiative, Disponível em: <https://www.globalreporting.org/standards> Acesso em: 01 jun. 2020.

INSTITUTO ETHOS. Parceria Ethos/GRI. Disponível em: <http://www.ethos.org.br/>Acesso em: 18 mar. 2011.

LARA, L. G. A. de; OLIVEIRA, S. A. de. A ideologia do crescimento econômico e o discurso empresarial do desenvolvimento sustentável. Cad. EBAPE.BR, Rio de Janeiro v. 15, n. 2, p. 1-23, 2017.

LEITE FILHO, G. A.; PRATES, L. A.; GUIMARÃES T. N. Níveis de Evidenciação dos Relatórios de Sustentabilidade das Empresas Brasileiras A+ do Global Reporting Initiative (GRI) no Ano de 2007. In: XXXIII ENCONTRO DA ASSOCIAÇÃO NACIONAL DE PÓS-GRADUAÇÃO E PESQUISA EM ADMINISTRAÇÃO (EnANPAD), 2009, Rio de Janeiro. Anais [...]. Rio de Janeiro: ANPAD, 2009. Disponível em: <http://www.anpad.org.br/>. Acesso em: 02 fev.2011.

LINS, L. S.; SILVA, R. N. S. Responsabilidade Sócio-Ambiental ou Greenwash: Uma Avaliação com Base nos Relatórios de Sustentabilidade Ambiental. Sociedade, Contabilidade e Gestão, Rio de Janeiro, v. 4, n. 1, 2009.

MADALENA J. D.; ROVES, S. FERREIRA, D. M. FERREIRA, L. F. Estudos dos relatórios de sustentabilidade GRI de empresas brasileiras. Revista Eletrônica em Gestão, Educação e Tecnologia Ambiental, Santa Maria, RS, v.20, n.1, jan./abr.2016. 
MATTAROZZI, V.; TRUNKL, C. Sustentabilidade no setor financeiro. São Paulo: Senac, 2008.

MAZZIONI, S.; DI DOMENICO, D.; ZANIN, A. A evidenciação da prática corporativa de ações de responsabilidade social com o uso do balanço social. Revista Catarinense da Ciência Contábil, Florianópolis, SC, v.9, n.27, p. 43-59, 2010.

MOTA, M. O; MAZZA, A. C.; OLIVEIRA, F.C. Uma análise dos relatórios de sustentabilidade no âmbito ambiental do Brasil: desenvolvimento sustentável, aumento de competitividade ou camuflagem organizacional? In: XXXIII ENCONTRO DA ASSOCIAÇÃO NACIONAL DE PÓSGRADUAÇÃO E PESQUISA EM ADMINISTRAÇÃO, 2011, Rio de Janeiro. Anais [...]. Rio de Janeiro: ANPAD, 2011.

OLIVEIRA, F. F. de; MOURA-LEITE, R. C. As práticas de responsabilidade social de empresas modelo em sustentabilidade. Revista Ciências Administrativas, Fortaleza, CE, v. 20, n. 1, p. 249284, 2014.

PAPASPYROPOULOS K. G.; BLIOUMIS V.; CHRISTODOULOU A. S. Environmetal reporting in Greece: The Athens stock exchange. African Journal of Business Management, v. 4, p. 26932704, 4 oct. 2010. Disponível em: 〈http://academicjournals.org/AJBM>. Acesso em: 18 jul. 2011.

PEREIRA, N. S. P.; PEREIRA, C. A.; MONTEIRO, R; P.; PAIXÃO FILHO J. M. Relatórios de sustentabilidade: ferramenta de interface no desempenho social, econômico e ambiental das organizações. RAGC, Monte Carmelo, MG, v.3, p. 55-70, 2015.

PEREIRA, R. S.; FARIA, A. C.; SOUZA, M. T. S. Análise de indicadores de sustentabilidade no segmento químico e petroquímico. In: Associação Nacional de Pós-Graduação e Pesquisa em Administração. In: XXXIII ENCONTRO DA ASSOCIAÇÃO NACIONAL DE PÓSGRADUAÇÃO E PESQUISA EM ADMINISTRAÇÃO, EnANPAD, 2009, Rio de Janeiro. Anais [...]. Rio de Janeiro: ANPAD, 2009. Disponível em: <http://www.anpad.org.br/> . Acesso em: 02 fev. 2011.

RIBEIRO, H. C. M.; GOMES, N. B.; SOUZA. Evidenciação das Informações sobre Emissões de GEE das Empresas Listadas no ISE Bovespa. In: XIV SIMPÓSIO DE ADMINISTRAÇÃO DA PRODUÇÃO, LOGÍSTICA E OPERAÇÕES INTERNACIONAIS, SIMPOI, 2011, São Paulo. Anais [...]. São Paulo: EAESP/FGV, 2011. Disponível em: <http://www.simpoi.fgvsp.br/>. Acesso em: 20 jul. 2011.

ROSA, F. S.; ENSSLIN, S. R.; ENSSLIN, L.; LUNKES, R. J. (2011). Gestão da evidenciação ambiental: um estudo sobre as potencialidades e oportunidades do tema. Engenharia Sanitária e Ambiental, Rio de Janeiro, v.26, v.1, p. 157-166, 2011. 
SCANDELARI, V. do R. N.; CUNHA, J. C. da. Ambidestralidade e desempenho socioambiental de empresas do setor eletroeletrônico. Revista de Administração de Empresas, São Paulo, v. 53, n. 2, p. 183-198, 2013.

TONOLLI, B. B.; ROVER, S.; FERREIRA, D. D. M. Influência dos investimentos ambientais e dos indicadores econômico-financeiros na seleção de empresas para compor o índice de sustentabilidade empresarial (ISE). Revista Catarinense da Ciência Contábil, Florianópolis, SC, v. 16, n. 48, p. 69-85, 2017.

\section{Dados dos autores:}

\section{Rosany Corrêa}

ORCID: https://orcid.org/0000-0002-2599-2742

Doutora em Administração pela Universidade Nove de Julho. Professora Adjunta da Universidade Estadual do Piauí (UESPI). Parnaíba, PI e Brasil. rosanycorrêa@ hotmail.com.

\section{Henrique César Melo Ribeiro}

ORCID: https://orcid.org/0000-0002-0704-1812

Doutor em Administração pela Universidade Nove de Julho. Professor Adjunto da Universidade Federal do Delta do Parnaíba (UFDPar). Parnaíba, PI e Brasil. hcmribeiro@gmail.com. 